\title{
Investments in lead-time reduction: How to finance and how to implement
}

\author{
Işık Biçer *a and Ralf W. Seifert ${ }^{\mathrm{b}, \mathrm{c}}$

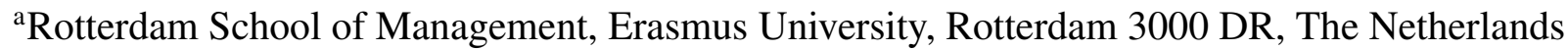 \\ ${ }^{b}$ Ecole Polytechnique Fédérale de Lausanne, CH-1015 Lausanne, Switzerland \\ 'IMD, Chemin de Bellerive 23, P.O. Box 915, CH-1001 Lausanne, Switzerland
}

\begin{abstract}
We consider a multi-period production problem in which a manufacturing firm produces a seasonal product to satisfy uncertain market demand in each selling period. The firm jointly determines the production quantity, working capital level, the amount of short-term debt, and dividends paid out to equity holders. It also has an option to raise capital by issuing long-term debt and invest in reducing lead times. Demand forecasts are updated according to a multiplicative martingale process. We formalize the problem by developing a Markov Decision Process (MDP) and characterize the structure of the optimal policy, which allows us to solve the problem in polynomial time. We show that debt (equity) financing is more beneficial for the products with low (high) demand uncertainty. Using our model, we propose a simple typology that shows effective investment strategies in reducing the lead time depending on demand uncertainty and the value added by production of each sub-component.
\end{abstract}

\section{Motivation and Description of the Problem}

It has been well established in both practice and academia that reducing lead times allows manufacturers to increase their profits by reducing inventory costs, stock-outs, and charging higher prices for responsiveness (Stalk 1988, Stalk \& Hout 1990, Suri 1998, Iyer \& Bergen 1997, Lutze \& Özer 2008). Manufacturers can reduce production lead times in different ways, such as cutting setup times and batch sizes, increasing the capacity of bottleneck operations, and re-engineering the production processes (Suri 1998). Suri (1998) developed a Lead-Time-Mapping Analysis, referred to as "Manufacturing Critical-Path Time (MCT) Analysis", that helps decision makers reduce the production lead time. In Figure 1, we present an example of the MCT chart for a product. One component and one sub-component are needed to process the final product. A raw material is required to process the sub-component. The white area indicates the waiting time, the brown area represents the processing time, whilst the pink path represents the longest time to produce the final assembly from scratch, referred to as the "Manufacturing Critical-Path Time (MCT)." If the manufacturer places a single production order for the final product at the beginning, where production schedules are frozen after placing the order,

${ }^{*}$ Corresponding author. Email: bicer@ $@$ rsm.nl 


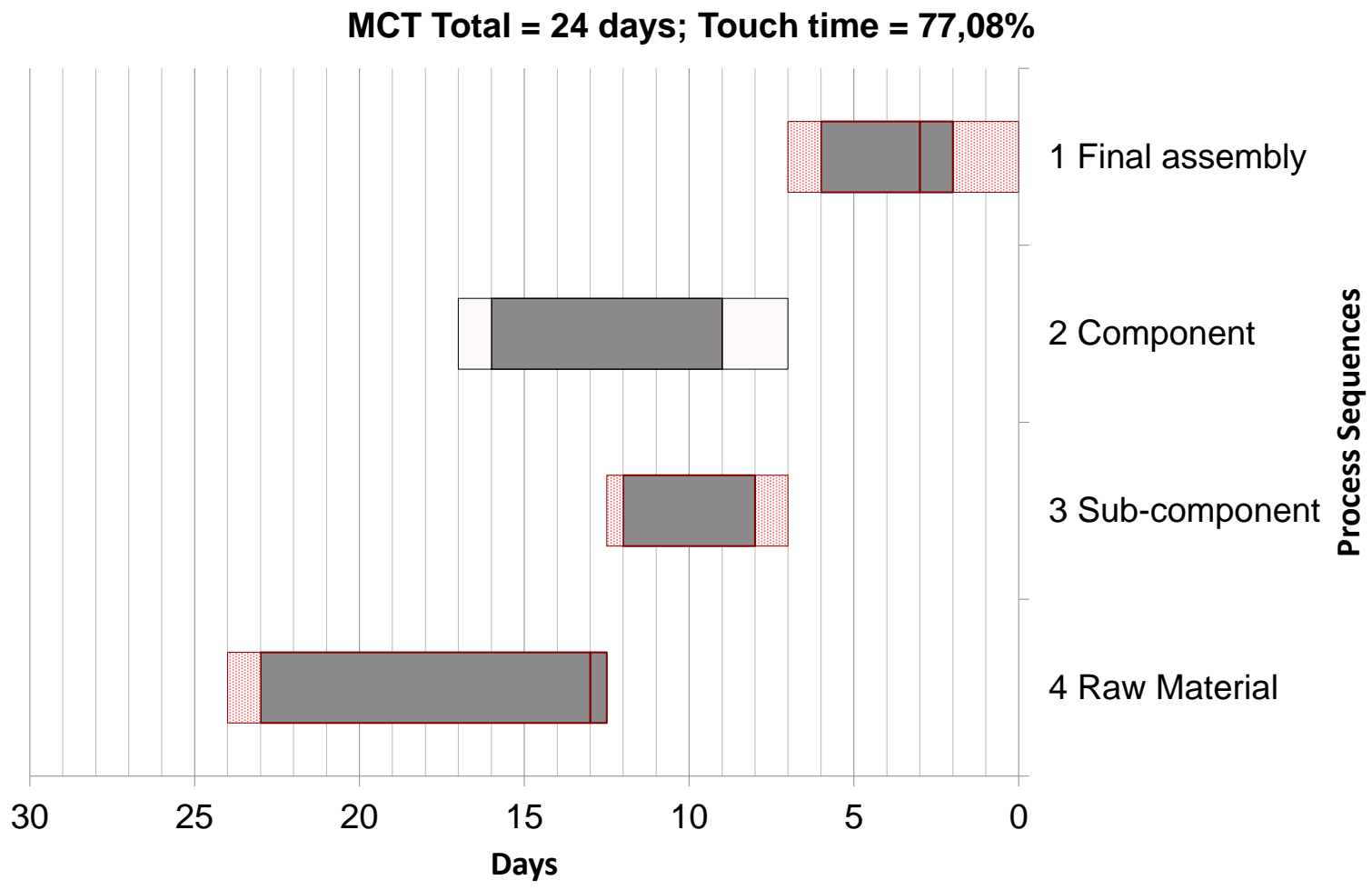

Figure 1: An MCT Chart for a Simple Manufacturing Model

the MCT value will give the production lead time. If the production schedules can be adjusted over time, the manufacturer can postpone the production decision of some components. Therefore, the latest time to start production of each component becomes a decision epoch. For example, the purchase order for the raw material should be placed 24 days in advance; the production order for the sub-component should be placed 12.5 days in advance. In such a setting, manufacturers should consider establishing a balance where some components are kept in inventory whilst the focus for others is to reduce the production lead time. This problem also arises in project supply chains (Seifert \& Markoff 2017).

In this research, we assume that a single production order is placed at the very beginning, which also includes the production and purchase orders of all components and raw materials. Production schedules are frozen after placing the production order; therefore, the MCT value gives the production lead time. Suri (1998) suggested that investments in reducing the lead time should aim to reduce the MCT. However, companies cannot easily make such investments due to high investment costs of capacity expansion (e.g., buying a new machine and hiring an operator) and setup-time reduction (e.g., developing automated quick changeover systems on existing machines). Therefore, high investment costs can be regarded as a major obstacle to developing marketresponsive strategies (Wood \& Heisz 2011). Nevertheless, market responsiveness reduces operational risk, which in turn makes debt financing more accessible. This may enable firms to use external funds and invest in 
reducing lead time. In this paper, we develop an analytical model that allows decision makers to analyze the following question:

1. What is the right financing strategy for investments in reducing the production lead time?

Answering this questions not only allows decision makers to better design their supply chains but also to better manage their firms' financial resources. However, practitioners often adapt a singular perspective and, in parallel, make investment decisions, which require the integration of both operational and financial dynamics of their firms. Until recently operations research scholars paid little attention to jointly modeling operational and financial problems (Protopappa-Sieke \& Seifert 2010). A relatively new research stream lying at the interface of operations management and finance has been aiming to fill this gap. Our research can be considered as a contribution to this research stream.

\section{Modeling Approach and Methodology}

We consider a multi-period production problem in which a manufacturing firm produces a seasonal product to satisfy uncertain demand in each period. The firm jointly determines the production quantity, working capital level, the amount of short-term debt, and dividends paid out to equity holders. Therefore, the firm faces a newsvendor-like problem in each period, which also includes the optimization of financial decision variables. It also has an option at the very beginning to raise capital and invest in reducing lead time. If the firm does not invest in reducing lead time, the production order has to be placed at the beginning of each period. The length of each period (e.g., a year) is denoted by $T$. The firm places a single production order in each period at time $t \in[0, T]$, which is a decision variable depending on the lead-time-reduction investment. The production ends in full at time $T$ right before customer demand is realized. The lead time is the time elapsed between placing the order and satisfying customer demand, which is fixed to $T-t$ in each period.

Our model applies to the manufacturers of fashion items (e.g., fashion apparel, toys) and innovative products (e.g., smartphones). In the toy and electronic product industries, most of the sales occur during the Christmas selling season, but companies need to schedule their production orders well in advance of the Christmas season (Johnson 2001, Wingfield \& Guth 2005). In the fashion apparel industry, companies sell their seasonal products predominantly in winter or summer but order them roughly four to six months in advance of the selling season (Gallien et al. 2015).

Demand forecasts are updated according to a multiplicative martingale process to capture the positive impact of lead-time reduction. We consider the continuous-time version of the multiplicative martingale model that can be represented by a geometric Brownian motion (Hausman 1969). Let $D_{t}$ denote the demand forecast at time $t$, where $\mu$ is the drift rate of the geometric Brownian motion, and $\sigma$ the volatility parameter. Then, the 
forecast-evolution process is:

$$
d D_{t}=\mu D_{t} d t+\sigma D_{t} d W_{t}
$$

where $W_{t}$ is the standard Brownian motion process. We assume that the following sequence of events occurs in period $i \in\{1,2, \cdots,+\infty\}$ :

1. The working capital level is equal to $y_{i}$ at the beginning of period $i$. The production quantity is not constrained by $y_{i}$ because the firm may use short-term debt to cover a portion of production expenses.

2. The firm determines the production quantity $q_{i}$ during a given period at time $t \in[0, T]$.

3. It may use short-term bank debt $b_{i}$ and immediately incur a borrowing cost $\rho_{i}\left(b_{i}\right)$, which is a convex increasing function of $b_{i}$ (i.e., $\rho_{i}^{\prime}\left(b_{i}\right)>0, \rho_{i}^{\prime \prime}\left(b_{i}\right)>0$ ). Therefore, the working capital level becomes $y_{i}+b_{i}-\rho\left(b_{i}\right)$ if the firm borrows $b_{i}$ from a bank.

4. It incurs a total production cost $c q_{i}$, where $c$ is the cost of the product per unit.

5. The production ends before the realization of actual demand.

6. Actual demand $X_{i}$ is realized at the end of the period (i.e., $t=T$ ). The firm's revenue from sales is equal to $p \min \left(q_{i}, X_{i}\right)+s \max \left(q_{i}-X_{i}, 0\right)$, where $p$ is the product price per unit, and $s$ denotes the salvage value per unit.

7. The principal of short-term debt (i.e., $b_{i}$ ) is paid to the bank.

8. Shareholders are paid $v_{i}$ as dividends.

The actual demand $X$ is realized at time $T$. Demand forecast at time $T$ is assumed to be fully accurate (i.e., $\left.D_{T}=X_{i}\right)$.

We develop a Markov Decision Process (MDP) to determine the optimal production quantity, short-term debt and dividend amounts for a given lead time and long-term debt level. We define two variables such that:

$$
\begin{aligned}
\mathfrak{L} & =\frac{B+c Q+\rho(b)-y-s Q}{p-s}, \\
\mathfrak{U} & =\frac{B+c Q+\rho(b)-s Q}{p-s} .
\end{aligned}
$$

The firm declares bankruptcy if demand turns out to be less than $\mathfrak{L}$, and it makes positive profit if demand turns out to be more that $\mathfrak{U}$. We have the state space such as $\mathbf{S}=\left\{S_{0}, S_{1}\right\}$ where $S_{0}$ denotes bankruptcy and $S_{1}$ 
denotes operating states. Then, the transition probabilities are given by:

$$
\begin{aligned}
& P\left(S_{0} \mid S_{1}\right)=P\left(D_{T}<\mathfrak{L}\right), \quad P\left(S_{1} \mid S_{1}\right)=P\left(D_{T} \geq \mathfrak{L}\right), \\
& P\left(S_{0} \mid S_{0}\right)=1, \quad P\left(S_{1} \mid S_{0}\right)=0 .
\end{aligned}
$$

Then, the Bellman equation indicating the total return to equity holders is written as follows:

$$
\begin{aligned}
V_{E}\left(S_{0}\right)= & 0, \\
V_{E}\left(S_{1}\right)= & \max _{y, Q, b, B}\left\{\mathrm{R}\left(S_{1} \mid y, Q, b, B\right)\right. \\
& \left.+\left(1+r_{0}\right)^{-1} P\left(S_{1} \mid S_{1}, y, Q, b, B\right) V_{E}\left(S_{1}\right)\right\},
\end{aligned}
$$

where $\mathrm{R}\left(S_{1} \mid y, Q, b, B\right)$ is the expected reward in state $S_{1}$ conditional on $y, Q, b$, and $B$.

Analytical derivations are presented in a more technical paper (Biçer \& Seifert 2017a). Our MDP model can be considered as a simplified version of $\mathrm{Li}$ et al. (2013), except that we include a forecast-evolution process to capture the cost of lead time. Unlike Li et al. (2013) where inventory level is a state variable, we assume that excess inventory is salvaged at the end of each period, making the inventory level equal to zero in the beginning of each period.

Standard methods of solving Markov Decision Processes include value-iteration and policy-iteration techniques. In the value-iteration algorithm, an initial value is assigned to each state and the optimal values for all the states are found by iterating the value function (Puterman 1994, pp. 160-164). In the policy-iteration algorithm, an arbitrary policy is selected and the value for the policy is calculated. Although rewards and transition probabilities depend on the selected policy, the value function is formulated in terms of states, not actions. To address this disconnection, the existing policy is updated by a better policy in each iteration until the algorithm converges (Puterman 1994, pp. 174-176). Hotz \& Miller (1993) and Hotz et al. (1994) provided an alternative representation by formulating the value function in terms of conditional choice probabilities. Their model allows estimating the value function based on agents' behavior, without solving the dynamic programming model. Their model has been proved to be very efficient because they eliminated the iteration of calculating the value function and updating the policy at each step. In Biçer \& Seifert (2017a), we develop analytical expressions for the transition probabilities, rewards, and the value function in terms of actions, not states. This allows us to eliminate the iteration of calculating the value function and updating the policy at each step. Thus, the optimal solution can be obtained in polynomial time. 


\section{Results and Insights}

We conducted a numerical analysis (Biçer \& Seifert 2017a) based on our analytical model to derive managerial insights. We first observed that the more the demand uncertainty, the higher the value of reducing the lead time. This result is very intuitive because it is well known in the extant literature that the value of lead-time reduction is positively associated with demand uncertainty. Our less intuitive result is that the percentage increase in equity holders' payoff as a result of lead-time reduction decreases with the profit margin of the product. When the profit margin is low, the manufacturer tends to produce very little to minimize stock-out costs. Thus, the target (optimal) working capital level is set to very low values for low profit-margin and long lead-time values. Reducing the lead time in such a case not only helps the firm reduce the demand risk but also favorably increase the optimal working capital level. This leads to a substantial increase in the return to equity holders for low profit-margin products when the lead time is reduced.

We also found that reducing the lead time is more beneficial to equity holders for lower demand uncertainty when the investment in lead-time reduction is financed by debt in an inefficient market. This result is counterintuitive because it is well known that the value of lead-time reduction increases in demand uncertainty. Yet, this effect can be fully attributed to debt financing in an inefficient market. Debt holders price the value of debt based on the existing risk exposure of the firm in an inefficient market. After the lead time is reduced, the decrease in the exposure to demand risk would give an additional benefit of lowering the risk to debt holders. Therefore, equity holders do not capture the full benefits of reducing the lead time when the investment is financed by debt in an inefficient market. The disadvantage for equity holders compared to debt holders increases proportional to demand uncertainty.

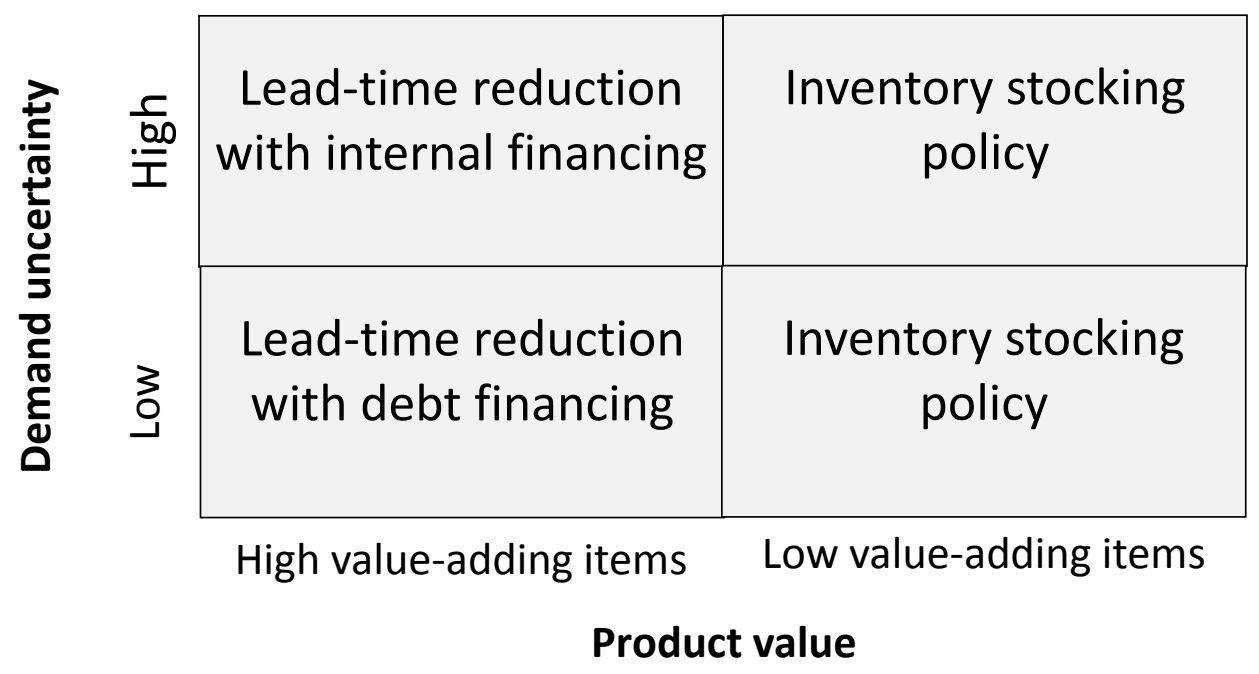

Figure 2: Lead-time investment typology

Based on our results, we propose a typology in Figure 2. Manufacturers are better off reducing the lead 
time for high value-adding items. High value-adding items are the raw materials or components for which the purchase or the production costs are relatively high, compared to other raw materials or components in the Billof-Materials. Likewise, low value-adding items are the raw materials or components for which the purchase or the production costs are relatively low. For low value-adding items, manufacturers can start production well in advance to pile up inventory. The investments in reducing the lead time should be financed through equityfinancing for high demand uncertainty, whereas debt financing should be used for low demand uncertainty.

\section{Future Research}

A recent study in the marketing field has shown that satisfying market demand when an unexpected increase in demand occurs (i.e., referred to as clumpy demand in marketing) is very critical to sustain profitability of retailers (Zhang et al. 2014). Biçer et al. (2017) developed a prescriptive-analytics model to analyze the value of reducing the lead time under demand shocks. They considered a jump-diffusion process to capture the impact of clumpiness and applied the inverse Fourier theorem to derive optimal results. They compared the jump model with a constant volatility model having the same level of volatility, and showed that ignoring the positive jumps or winsorization leads to underestimation of the value of reducing the lead time. The research by Biçer et al. (2017) has shown that lead-time reduction helps companies satisfy marketing-related objectives, which have been changing tremendously over the last decade due to the advances in information technology, online marketing, and technology adoption of customers. However, there is still a gap in both literature and practice such that it is necessary to develop new models to price the value of operational flexibility strategies (e.g, lead-time reduction, sourcing flexibility, and quantity flexibility) depending on the changes in the purchasing behavior of customers.

One of our limitations is the assumption that a single production order is placed at the beginning, and then the production schedules are frozen. Companies that follow time-based manufacturing strategies often have the flexibility to update production orders over time (Biçer \& Seifert 2017b). In such a setting, the latest time to start production of each component becomes a decision epoch. In such a setting, the order quantity in each decision epoch has an upper bound determined by the order quantity in the previous decision epoch. This problem can be formulated as a dynamic programming (DP) model. The solution of this problem would help to derive useful insights regarding the determination of critical operations for which investing in reducing the lead time is highly profitable. We suggest that the analysis of this problem would be an interesting topic for future research. 


\section{References}

Biçer, I., Hagspiel, V. \& de Treville, S. (2017), Valuing supply-chain responsiveness under demand shocks. Working paper, Erasmus University, Rotterdam, The Netherlands.

Biçer, I. \& Seifert, R. W. (2017a), Financing and implementing lead-time-reduction investments. Working paper, Erasmus University, Rotterdam, The Netherlands.

Biçer, I. \& Seifert, R. W. (2017b), 'Optimal dynamic order scheduling under capacity constraints given demandforecast evolution', Production and Operations Management .

Gallien, J., Mersereau, A. J., Garro, A., Mora, A. D. \& Vidal, M. N. (2015), 'Initial shipment decisions for new products at Zara', Operations Research . DOI: 10.1287/opre.2014.1343.

Hausman, W. H. (1969), ‘Sequential decision problems: A model to exploit existing forecasters’, Management Science 16(2), B93-B111.

Hotz, V. J. \& Miller, R. A. (1993), 'Conditional choice probabilities and the estimation of dynamic models', The Review of Economic Studies 60(3), 497-529.

Hotz, V. J., Miller, R. A., Sanders, S. \& Smith, J. (1994), 'A simulation estimator for dynamic models of discrete choice', The Review of Economic Studies 61(2), 265-289.

Iyer, A. V. \& Bergen, M. E. (1997), 'Quick response in manufacturer-retailer channels', Management Science 43(4), 559-570.

Johnson, M. E. (2001), 'Learning from toys: Lessons in managing supply chain risk from the toy industry', California Management Review 43(3), 106-124.

Li, L., Shubik, M. \& Sobel, M. J. (2013), 'Control of dividends, capital subscriptions, and physical inventories', Management Science 59(5), 1107-1124.

Lutze, H. \& Özer, Ö. (2008), 'Promised lead-time contracts under asymmetric information', Operations Research 56(4), 898-915.

Protopappa-Sieke, M. \& Seifert, R. W. (2010), 'Interrelating operational and financial performance measurements in inventory control', European Journal of Operational Research 204(3), 439-448.

Puterman, M. L. (1994), Markov Decision Processes, John Wiley \& Sons, Hoboken, New Jersey.

Seifert, R. W. \& Markoff, R. (2017), 'Project supply chains - a different world: The overlooked supply chain model', IMD - Tomorrow's Challenges (44). 
Stalk, G. (1988), 'Time: The next source of competitive advantage', Harvard Business Review 66(4), 41-51.

Stalk, G. \& Hout, T. M. (1990), Competing against time: How time-based competition is reshaping global markets, The Free Press, New York, NY 10020.

Suri, R. (1998), Quick response manufacturing: A companywide approach to reducing lead times, 1 edn, CRC Press, Boca Raton, FL.

Wingfield, N. \& Guth, R. A. (2005), 'Why shortages of hot gifts endure as a christmas ritual', Wall Street Journal .

URL: http://www.wsj.com/articles/SB113348637265111973

Wood, D. \& Heisz, M. (2011), 'C.R. Plastics', Case Study: Richard Ivey School of Business . Product \#: W11581-PDF-ENG.

Zhang, Y., Bradlow, E. T. \& Small, D. S. (2014), 'Predicting customer value using clumpiness: From RFM to RFMC', Marketing Science 34(2), 195-208. 